\title{
PI, PID \& Fuzzy Controller Based Constant Speed BLDC Motor on Propulsion Application using MATLAB / SIMULINK
}

\author{
Kvns Pavan Kumar, S.Prakash
}

\begin{abstract}
Here this paper tells about an advance brushless DC motor with effective performance by electronic forcible structure in electric vehicles (EV's) with cost effective and hybrid electric vehicles (HEV's). The project includes comparison of three different controllers and development of PI, PID \& fuzzy Based digital controller for BLDC motor. The project involves literature survey of three different controllers applicable to constant speed and current control using MATLAB/SIMULINK. The speed and stator current of $B L D C$ is measured by the rate limiter during the step change at reference voltage using $D C$ link. The design ,model and performance of the proposed $B L D C$ driven voltage control PFC converter is replicated in matlab-simulink for air conditioning compression done by the BLDC motor at a speed of 2000 rpm with $1.5 \mathrm{~kW}$. The evaluated result of the proposed system presents a speed control of PI, PID and fuzzy for demonstrating an improved effective driven system by PFC features by huge range of constant speed and $A C$ input voltage. The control algorithm should be robustly designed to include position, rapidity controller of BLDC motor.
\end{abstract}

Keywords: PI, PID FLC (fuzzy logic control), BLDC motor, $P W M$, hall sensors, power factor correction (PFC)

\section{INTRODUCTION}

Due to huge environmental concerns we offer a promising solution for reducing vehicle emission for growing interest in hybrid (HEV) and non-hybrid vehicles (EV) which solves the main problem of internal combustion motor (ICE). Since the progression in battery innovation has been moderately drowsy, contrasted and the power gadgets territory, the impairment of close related by EV still remains. With this innovation confinement, the HEV is by all accounts the practical option in contrast to the ICE vehicle at the present [I]. Half and half electric vehicles can be delegated arrangement and parallel designs, as appeared in Fig.1. Hybrid Brushless Direct Current (BLDC) motors are used in huge range of presentations for example Aerospace, Medicinal hardware and so on.

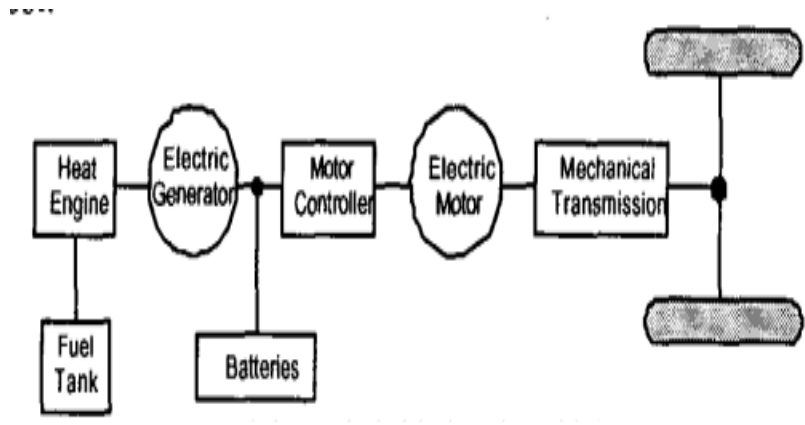

Fig 1. Structure of Hybrid electric vehicle mechanism

This is a result of great effectiveness, extensive rapidity run and great rotation comparative with motor size. Here not utilizing as given

Advantages:

- Here no sparks throughout the procedure that allows utilizing motor hazard areas.

- Here it has no noise for sparks commutating

- It has low maintenance cost due to long life brush replacement and smaller size

- Friction less commentator

Speed control is the way toward altering the electronic power conveyed toward motor to accomplish a specific rapidity is required. Alternative reason for rapidity controlling is due to the reason of keeping the motor speed steady by redistribute aggravations in torque. There are two fundamental strategies for supervising the rapidity, the Relative necessary subsidiary supervisor, I, PID, fuzzy supervisor. In both regular PI, PID and fuzzy supervisors are talked about. In the event of motor speed controller, utilizing subordinate share increment the impact of commotion, so here modern applications do not utilize whichever subsidiary shares present in controller, so here mechanical presentations of a PI supervisor is utilized for reducing the issue and incrementing the system sound. This paper tells about the subsidiary share incremented from zero to a PI and PID controller which is utilized. Albeit modern controller structures rely upon PI and PID supervisors, the vast majority presentations are nonlinear (temperature control), and PI and PID altering on behalf of nonlinear systems is exceptionally troublesome. Then again, Fuzzy controllers are utilized for nonlinear systems, yet needs great learning by this structure for alteration. 


\section{PI, PID \& Fuzzy Controller Based Constant Speed BLDC Motor on Propulsion Application using MATLAB / SIMULINK}

\section{Operation \& Control Strategy}

These BLDC motors are also known as synchronous motors that imply the attractive arena produced by stator and the attractive arena created by rotor pivot as a similar recurrence. BLDC motors don't encounter "slip" which is typically found in enlistment motors. BLDC motors arrangement come across the 3 stages comparatively depending on windings. Out of the 3 stage motors the well-known motor is generally used for applications depending on windings.

\subsection{Stator}

The stator of a BLDC motor comprises loaded steel covers by winding set of openings depending on winding of internal fringe (appeared in Figure 4). Customarily, the stator looks like the acceptance motor so in that case the winding appropriated with another way. Maximum BLDC motors require 3 stator winding connected with star design. Every winding is built by numerous loops unified by shape of a winding. Here at least one winding is put into space for interconnecting and making a winding. Each winding is scattered over stator outer side for quantity depending on number of windings stated as trapezoidal and sinusoidal motors.

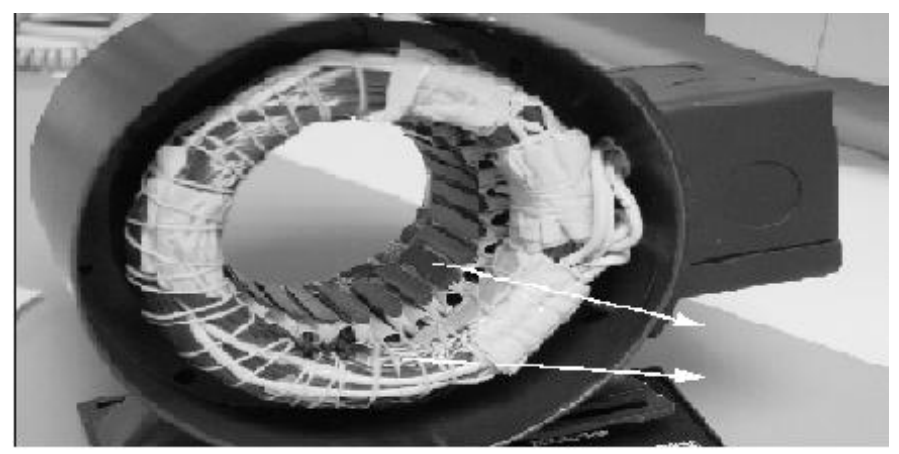

Fig. 2 Stator of BLDC Motor

\subsection{Rotor}

The rotor is manufactured by changeless magnet so it fluctuates from north to south shafts depending on one to 8 post sets. So here depending on the necessary gorgeous field thickness present in rotor, the best possible attractive substance is picked for making the rotor. Ferrite magnets are generally utilized for making changeless magnets. So the innovation progresses, uncommon ground compound magnets are picking up fame. The ferrite magnets are more affordable however there is a detriment of low motion thickness for given volume. Conversely amalgam substances have attractive thickness for each capacity and empower the rotor to pack additionally a similar torque.

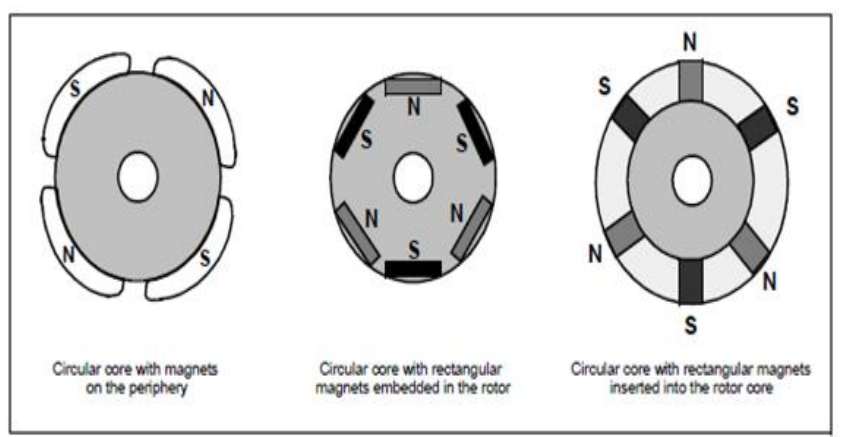

Fig.3 rotor magnet cross sections

\subsection{Hall Sensors}

Not in the least such as a brushed dc motor, is the recompense of a BLDC engine organized by electronic means to transform those BLDC motor, those stator winding ought to on the enabled on a plan. It will be discriminating on figure it out those rotor position something like that likewise will fathom which winding will a chance to be enabled then afterward the fortifying course of action. Rotor position may be distinguished using corridor sway sensors introduced under that stator. Most BLDC motors need 3 corridor sensors embedded under those stator on the non-driving complete of the engine. At whatever perspective the rotor magnetic shafts try near those $\mathrm{H}$ sensors, they provide for An secondary alternately low sign, demonstrating those $n$ alternately met through urban decay for the reason of deindustrialization, engineering concocted, government policies for setting off the near sensors. In perspective of the mix about these three corridor sensor flag, the exact progression for supplanting could make determined.

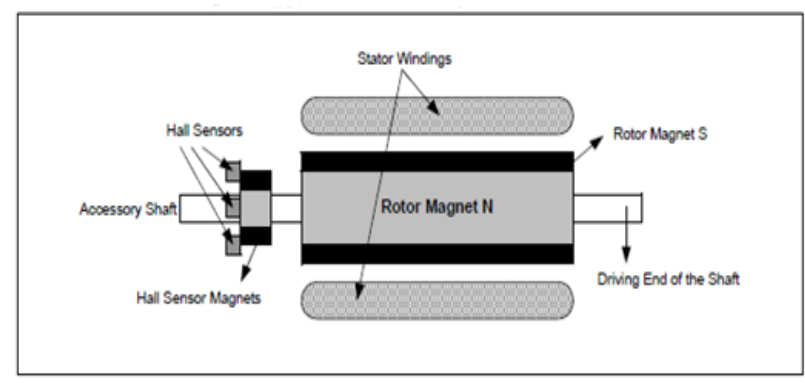

Fig.4 BLDC motor transverse section

\section{PI CONTROLLER}

The goal from any controller is with farthest point the screw up the middle of those true yield, which if need been controlled, and the perfect gas yield, which will be known as the set point. By virtue of speed control this misstep might a chance to be communicated by those going with condition: $\mathrm{e}(\mathrm{t})=\omega \mathrm{SP}(\mathrm{t})-\omega \mathrm{PV}(\mathrm{t})(1)$

the place $e(t)$ may be the screw up ability about time, $\omega$ SP $(t)$ is the reference speed or the pace set point Similarly as limit from claiming time, Furthermore $\omega P V(t)$ will be the true engine velocity as limit of period. Those PI statement speaks to Proportional essential analytics Derivative, thus At whatever PI controller could a chance to be disconnected under 3 areas each a major aspect need its Gain, the starting section is the relating Some piece witch will be the screw up expanded by a unfaltering expansion which is KP. Those ensuing some piece will be the key part, which may be the joining about screw up with period expanded toward a steady addition, which will be ki. Those third a piece may be that subsidiary part, which is the subordinate for botch for time expanded toward an enduring expansion which is KD. Those PI controller state camwood be communicated as.

\section{A. $u t=K$ Ket + KIetdt (2)}

Here ut is the PI yield, KP is the corresponding addition, $\mathrm{KI}$ is the essential increase, $\mathrm{KD}$ is the subsidiary increase, and $\mathrm{e}(\mathrm{t})$ is the blunder capacity appeared in condition (1). The accompanying capacity obstruct in fig 4 , clarifies the activity of the PI controller. 


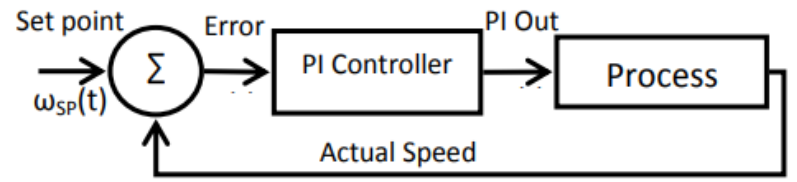

Figure 5 PI Controller Block Diagram

1. PID (Three Terms) Controllers

Relative activity: reacts rapidly to changes in blunder deviation. Necessary activity: is slower yet evacuates balances between the plants yield and the reference.

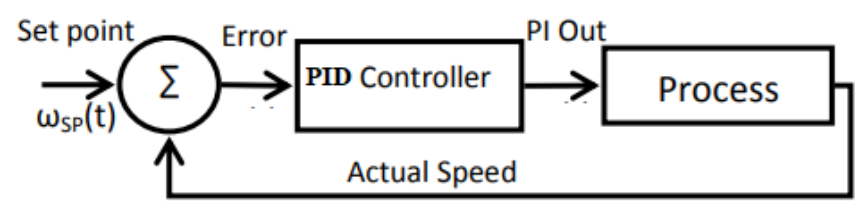

Figure 6 PID Controller Block Diagram

Subsidiary activity: Speeds up the framework reaction by including control activity corresponding to the pace of progress of the input mistake. Next this is helpless to commotion in the blunder signal that restricts subsidiary increase. Present this authorities more approximations of KP and KI (littler TI) to be utilized than conceivable in unadulterated PI controllers, yet huge estimations of subsidiary addition (KD) will cause insecurity.

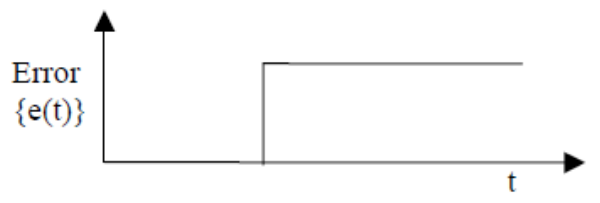

The PID regulator is given by:

$$
\begin{gathered}
u(t)=K_{P}\left[e(t)+\frac{1}{T_{I}} \int e(t) d t+T_{D} \frac{d e(t)}{d t}\right] \\
K_{I}=\frac{K_{P}}{T_{I}} \quad K_{D}=K_{P} T_{D} \\
\frac{U(s)}{E(s)}=K_{P}+\frac{K_{I}}{s}+K_{D} s=\frac{K_{D} s^{2}+K_{P} s+K_{I}}{s}=\frac{N(s)}{D(s)}
\end{gathered}
$$

NB: this transfer function is non-proper and is therefore difficult to realize in practice.

Proper T.F.: Order N(s) £ Order D(s)

Strictly proper T.F.: Order N(s) < Order D(s)

Here this is easier to realize for reducing the susceptibility and derivability actions of noise.

\subsection{Fuzzy PI Controller}

Fuzzy controller is a computed controller subject to fuzzy justification. Fuzzy controllers depend upon norms and state the middle of commitments on get those yield. Fuzzy controller's standards need aid clinched alongside wording that human might fathom like tall, short, medium stature, thus it may be simpler for mankind's should arrangement on the off risk that he need An great Taking in something like those skeleton that ought further bolstering need been regulated. Those commitments of the fuzzy controller need aid mapped should particular qualities called fuzzy sets. At whatever fuzzy controller comprises about three areas see in Fig 6
Fuzzification is a way to change over the simple contribution for the estimation of fuzzy sets utilizing enrollment work. Rule Base is the strategic guidelines, conditions between the contributions for getting the output.

Defuzzification is a procedure which converts the structure output from the fuzzy sets esteems to simple output esteem.

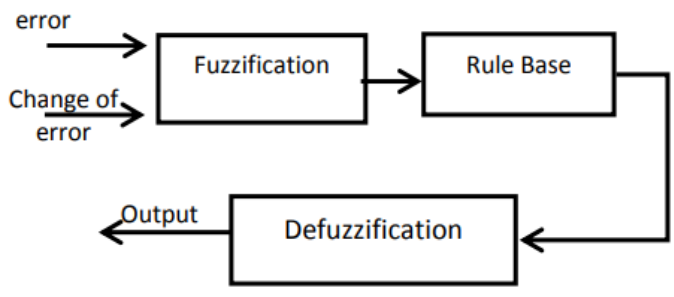

Figure 7 Fuzzy Controller Block Diagram

Maximum fuzzy supervisors utilize a rectangular enrollment capacity plus binary fuzzy sets or added can be utilized. The added fuzzy sets utilized the greater solidness and improved execution accomplished, yet in addition greater multifaceted nature the framework progresses toward becoming.

\section{Comparative STUDY}

In [3] a PI steady rapidity controller and a fuzzy PI rapidity controller is utilized for controlling the rapidity of a BLDC motor through similar limitations utilized by this paper. Table 1 demonstrates an examination between the presentation in the two papers together i.e. PI, PID controller and Fuzzy controller.

In [3], if there should arise an occurrence of PI and PID controller, the relaxing time by initial step (from 0 to 700 $\mathrm{RPM}$ ) is $0.06455 \mathrm{sec}$. furthermore they arise the occurrence

\begin{tabular}{|c|c|c|c|}
\hline \multicolumn{4}{|c|}{ Reference [3] } \\
\hline \multirow[t]{2}{*}{ speed } & \multicolumn{3}{|c|}{ Conventional PI Controller } \\
\hline & \multicolumn{2}{|l|}{$\operatorname{Tr}$} & Ts \\
\hline $0-700$ & \multicolumn{2}{|l|}{0.04} & 0.06455 \\
\hline $700-900$ & \multicolumn{2}{|l|}{0.005} & 0.007 \\
\hline speed & \multicolumn{3}{|c|}{ Fuzzy PI Controller } \\
\hline $0-700$ & \multicolumn{2}{|l|}{0.039} & 0.05972 \\
\hline $700-900$ & \multicolumn{2}{|l|}{0.01} & 0.018 \\
\hline \multicolumn{4}{|c|}{ Proposed Controller } \\
\hline Speed & \multicolumn{3}{|c|}{ Conventional PIDController } \\
\hline $0-700$ & 0.005 & \multicolumn{2}{|l|}{0.025} \\
\hline $700-900$ & 0.005 & \multicolumn{2}{|l|}{0.0075} \\
\hline Speed & \multicolumn{3}{|c|}{ Fuzzy Controller } \\
\hline $0-700$ & 0.02 & \multicolumn{2}{|l|}{0.023} \\
\hline $700-900$ & 0.004 & \multicolumn{2}{|l|}{0.005} \\
\hline
\end{tabular}
of Fuzzy controller, the relaxing time is $0.05972 \mathrm{sec}$.

\section{Table 1: Comparative Study of PI, PID, Fuzzy}

The opposite presentation parameters would evacuate starting with the response velocity twist for both those PI and PID controller and the fuzzy controller. 


\section{PI, PID \& Fuzzy Controller Based Constant Speed BLDC Motor on Propulsion Application using MATLAB / SIMULINK}

From the above table it is clearly mentioned that beginning step (from 0 to 700 RPM), suggested PI controller execution may be better, as those suggested particular case need a greatly minimal rising time, which will be $0.005 \mathrm{sec}$. and, it may be stretched clinched alongside security without motions. Those suggested PI controller need similarly a minimal relaxing time that may be $0.025 \mathrm{sec}$ for no overshoot. To those resulting propel (from 700 on 900 RPM), the presentation of the recommended PI controller will be nearly equal to one, and the velocity will be extended for reliability also. The startup torque in the suggested PI controller will be regarding $7.9 \mathrm{~N} . \mathrm{M}$ in the introductory step, yet on [3] the start dependent upon torque is around $3 \mathrm{~N}$. M. Those starting dependent upon present in the recommended PI Also PID controller may be around 6A, same time On [3], the startup present will be 4 a. In this way in [3], a more diminutive start up present may be finished effectively, yet for low start-up torque. Starting with those fuzzy PI controller, clearly in the beginning venture (from 0 will 700 RPM), the recommended fuzzy controller execution is improved, Likewise those suggested you quit offering on that one need a exceptionally little rising time, which may be $0.02 \mathrm{sec}$. and, little relaxing period are $0.023 \mathrm{sec}$ for no overshoot.

Table 2: Comparative Study among PI, PID and Fuzzy Controller.

\begin{tabular}{|c|c|c|c|}
\hline \multicolumn{2}{|l|}{ Parameter } & \multirow{2}{*}{$\begin{array}{l}\text { PI \& PID } \\
\text { Controller }\end{array}$} & \multirow{2}{*}{$\begin{array}{l}\begin{array}{l}\text { Fuzzy } \\
\text { Controller }\end{array} \\
0.02\end{array}$} \\
\hline \multirow{2}{*}{ Rise Time } & 0-700 RPM & & \\
\hline & 700-900 RPM & 0.005 & 0.004 \\
\hline \multirow{2}{*}{$\begin{array}{l}\text { Settling } \\
\text { time }\end{array}$} & 0-700 RPM & 0.025 & 0.023 \\
\hline & 700-900 RPM & 0.0075 & 0.005 \\
\hline \multirow{2}{*}{$\begin{array}{l}\text { Steady state } \\
\text { error }\end{array}$} & 0-700 RPM & $0 \%$ & $0.7 \%$ \\
\hline & 700-900 RPM & $0 \%$ & $0.7 \%$ \\
\hline \multirow{2}{*}{$\begin{array}{l}\text { Start-up } \\
\text { torque }\end{array}$} & 0-700 RPM & 7.9 N.M & 2.1 N.M \\
\hline & 700-900 RPM & 2.2 N.M & 2.3 N.M \\
\hline \multirow{2}{*}{$\begin{array}{l}\text { Start-up } \\
\text { Current }\end{array}$} & 0-700 RPM & $6 \mathrm{~A}$ & $2 \mathrm{~A}$ \\
\hline & 700-900 RPM & $2 \mathrm{~A}$ & $2 \mathrm{~A}$ \\
\hline $\begin{array}{l}\text { Speed } \\
\text { Variations }\end{array}$ & \multicolumn{2}{|l|}{$0.8 \%$} & $0.6 \%$ \\
\hline
\end{tabular}

\section{CONCLUSION}

A BLDC motor speed controller is displayed utilizes both PI and PID controller, and Fuzzy controller. A similar report is generated among the introduced PI, PID and Fuzzy controller. Here the utilized situations to assess displayed speed controllers' presentation. When all is said in done the displayed speed controllers give excellent execution. An examination among the exhibited PI and PID speed controller and the fuzzy speed controller as well, obviously the presentation of the fuzzy speed controller is all in all superior to the PI and PID speed controller. An upcoming effort is possible to improve current control capacity of the present speed controller, now the current is retained inside the specific range on behalf of specified speed for improving the motor startup current, decreasing the motor current waves plus upgrading the motor torque attributes. Additionally by current control, the speed and torque varieties are decreased for least, by dodging by abrupt variations in the motor current.

\section{REFERENCES}

1. G. Liu, S.Chen, S. Zheng, X.Song, „Sensorless low-current start-up strategy of $100 \mathrm{KW}$ BLDC motor with small inductance eee, IEEE Trans, Ind. inform.,vol. 13, pp.1131-1140, June.2018.

2. S. Chen, G. Liu, and L Zhu. ,, Sensorless control strategy of a $315 \mathrm{Kw}$ high-speed BLDC motor based on a speed independent flux linkage function $^{\text {eeee }}$, IEEE Trans, Ind. Electron.,vol. 32, pp.8607-8617, nov.2018.

3. Ali. Mousmi, ahmed. Abbou and Yassine El Houm, ,,,Trapezoidal control of brushless DC motor based on DSP F28335 ceee, IEEE International Conference on Wireless Technologies, Embedded and Intelligent Systems (WITS), 2018.

4. T. Shi, Y. Cao, G. Jiang, X. Li, and C. Xia, "A Torque control strategy for Torque Ripple reduction of Brushless DC Motor with Nonideal Back Electromotive Force", IEEE Trans. Ind. Electron, vol. 64, no. 6, pp. 4423-4433, June 2018.

5. M. Skóra, "Operation of PM BLDC motor drives with faulty rotor position sensor", 2018 International Symposium on Electrical Machines (SME), pp. 1-6, 2018. 